\title{
Revised guidelines for authors of gene mapping reports
}

This Journal suffers an embarrassment of riches in respect to the Gene Mapping, Cloning and Sequencing section. Although we are very pleased that this section is so well received by our authors and readers, we are running out of space and cannot accommodate the ever-increasing number of reports received for this section. Consequently, we must be more stringent in our acceptance criteria for submissions to this section.

The original intent of the short report format for gene mapping was to facilitate the transfer of information on map positions to the literature in such a way that the reader would be better informed on precisely how the gene was mapped than might be possible from a database entry. The format was also designed to facilitate the transfer of data into databases and to make sure that none of the relevant information was omitted from the report. The reports were largely expected to describe the first mapping of a gene, frequently at the level of the chromosome band. It was also expected that some reports would describe a refinement in the mapping of genes previously mapped to whole chromosomes or to chromosome arms. Moreover, mapping has changed and this is a further reason for developing more stringent criteria for gene mapping reports.

Below are the requirements that gene mapping reports must meet to be considered for publication:

1. The gene must be previously unmapped by any technique. This means that papers of mapping confirmations will no longer be accepted. Relocations of genes incorrectly mapped within a major chromosome band, i. e., to a different subband, will no longer be accepted. However, genes that are relocated a significant distance from the one to which it had been assigned, or to another chromosome, will be accepted. The evidence for the new assignment must be obtained with two different methods.
2. Well-described flanking markers must be given for all mapping assignments. The relative location of the flanking markers can be established by standard radiation hybrid or mouse backcross panels. For mapping by fluorescence in situ hybridization (FISH), the markers must be within $5 \mathrm{cM}$ or $5 \mathrm{Mb}$ of the gene or genes that have been mapped.

3. The results from DNA sequence database searches must be given for the mapped gene(s). The entire sequences should not be given, just the size, degree of the matches and their significance. If several sequences are involved, this should be presented in a concise table listing the standardized gene names as established by the HUGO Gene Nomenclature Committee and accession numbers of the matching sequences. The human chromosome reference sequences nucleotide positions of genes should also be given as they become available. (For further details on standardized gene names and the general requirements for gene mapping reports see the 'Guidelines for Authors' section of any recent issue of this Journal or at www.karger.com/journals/ccg/ ccg_gl.htm.).

4. The following categories must be collected into a single publication if submitted from one group of investigators: (a) All cDNAs representing a single multigene family. (b) Genes located within a single chromosome band. (c) A series of orthologous genes when results of comparative mapping studies of mouse (or some other species) and human genes are reported. When many genes are involved extra pages may be allowed.

Authors of both accepted and not accepted papers are encouraged to submit their data to mapping databases. The Genome Database (www.gdb.org) is prepared to accept the data if presented in the short report format.

Harold P. Klinger
KARGER Fax +41613061234 E-mail karger@karger.ch (c) 2000 S. Karger AG, Basel www. karger.com
Accessible online at: www. karger.com/journals/ccg 